\title{
Implementation of Competence Approach with Simulation Technology
}

\author{
Irina N. Raptanova, Maria.V. Shcherbakova*, Anna S. Fomichenko, Olga V. Strizhkova, and Elena A. Mokritskaya \\ Orenburg state university, pr. Pobedy 13, Orenburg, The Russian Federation
}

\begin{abstract}
The modernization of higher education is mandatory condition for the current stage of Russian society development and the ensuring of the Russian economy competitiveness. One of the priority issues of modernization is the strengthening of the significance of self-students studying. This is due primarily to the considerable reduction in the number of classroom sessions and the increase in hours provided for self-students studying. Self-studying becomes the basis for the professional development of a bachelor, encourage his cognitive interests, promotes the essential objectives of the training, that is, the formation of communicative and professional competences. The nature of the relationship between the teacher and the bachelor alters within the framework of competence-oriented education. The teacher, released from the mere transfer of knowledge, gets freedom in choosing forms of interaction or rather in choosing the methods used in such field of studying as "Foreign Language". Classical teaching methods are replaced with new ones. The emergence of information and communication technologies led to their rapid introduction into the educational process. The organization of self-students studying through the use of information and communication technologies is of great interest to many educational specialists. The specific nature of information and communication technologies lies in the creation in the educational process of various kinds of relations and conditions of real life, requiring from bachelors not only the knowledge of work-related material, but also their familiarization with a given image, a holistic immersion in the professional environment. The use of simulation technology facilitates the formation of cognitive-search activity of bachelors, causes incentive for learning a foreign language.
\end{abstract}

\section{Introduction}

Today, the implementation of a competence approach in conditions of higher education holds a special place. The aim of higher education, being a priority and system-forming field, is to prepare not only a good performer of professional functions, but also an actor of occupational activity, able to set goals and achieve them through independent decision-making, ready for selfdevelopment and self-fulfillment in their future career. The competence approach in education appeared as an alternative to the traditional educational system. Competence is the main educational result. A.V. Khutorsky interprets competence as an integrative characteristic of the bachelor's professional potential consists of value-motivational, cognitive and activity orientated components, which enable him to carry out professional activities. [1].

The idea of competence-oriented training is reflected in the Federal Education Act of November 8, 2013 No. 1245 , which states that "vocational training is aimed at the development of professional competencies by persons of various ages". Knowledge and skills are considered as auxiliary components for achieving the main goal that is the professional activity as a whole.
Competence is defined as a determined specification of the higher education programs to its result that is the corpus of knowledge, skills and abilities that a student must acquire as a result of training and the ability to apply them in practice. The shift of the ultimate goal of education from knowledge to "competence" allows solving a typical for Russian universities' challenge, when students can master theoretical knowledge, but experience significant difficulties in the integration of this knowledge for particular tasks. Thus, the imbalance between education and real life is restored.

The competence approach assumes the main objective of the educational process is to create conditions for the development of a self-experience in solving the cognitive, communicative, organizational, moral, and other issues that constitute the content of education [2]. In view of the specific of the teaching of the "Foreign Language" the basis for forming communicative competence among bachelors, in our opinion, is the effective use of advanced pedagogical and information communication technologies. Objectively speaking, communication can be considered an essential and universal condition for human life and one of the fundamental pillars of the social existence. Communicative competence is the ability to carry out

* Corresponding author: blackorchid777@ rambler.ru 
speech activity, pursuing communicative speech behavior on the basis of phonological, lexicalgrammatical, sociolinguistic and regional knowledge and skills according to various tasks and situations of communication.

Foreign language communicative competence, as a part of integrative communicative, one presupposes, first of all, as the acquisition of linguistic competence [3]. The latter encompasses awareness of a foreign language, the skills to correlate linguistic means with the tasks and conditions of communication, understanding of relations between communication participants, the ability to organize speech communication, taking into account social norms of behavior and the communicative expediency of utterance [4]. In the most general term, the communicative competence of an expert can be described as a certain level of personal and professional experience of interaction with society to operate successfully in the professional sphere and in society within person's abilities and social status.

The set of communicative knowledge and skills that make up the communicative competence of a person comprises:

- awareness of the rules and norms of communication;

- high level of speech development;

- ability to socialize;

- ability to meet the communication goal;

- ability to influence the interlocutor;

- ability to create a positive perception of one's own personality.

The modern graduate is a highly-skilled professional, combining intelligence with specialized areas of competence, able to identify strategic issues, to establish mutual understanding and interaction with the public, a specific social group, individuals, i.e., with a deep culture of communicative activity [5].

As already mentioned, the establishment of bachelors' communicative competence is possible with the active use of interactive technologies. The global Internet is the most promising form of communication and information exchange among people. It offers great opportunities for obtaining any information, including authentic materials. In addition to textual information, Internet technologies allow the use of sound files, video recordings, graphic information, which significantly stimulates the students' activity [6]. Global communications network empowers to organize debates between lectures and bachelors within and outside the university. The debates acquires a non-linear nature, and everybody is welcome to make a statement on the matter currently under discussion. Use of Web-based technology provides situations of practical use of language through intercultural communication with a native speaker.

As we noted above, according to educational standards, the implementation of the competence approach in the teaching of "Foreign Language", should occur within an interactive learning. In view of the fact that at present total hours for "Foreign Language" study has significantly decreased, it is worthwhile to consider the enforcement of this approach in the framework of organizing self-studying with the use of interactive technologies [7]. Under the implementation of the competence approach in the framework of organizing self students studying, we mean:

- vocational and personal relevance of the final outcome;

- action oriented;

- opportunity for creativity;

- ensuring the Bachelor's motivation and value attitude towards self-studying;

- the organization of self-students studying with ITsupported technologies;

- control over the self-studying by monitoring the process of graduates' occupational development.

In search of new information and communication technologies, as an effective means of organizing selfstudying, we are guided by the technology of simulation. In the explanatory dictionary, "technology" is defined as a set of techniques and practices applied in any case, skill, or art. We consider that simulation technology includes a number of techniques and practices used in the bachelors' academic activity ("context planning", "performance-oriented planning"). The technology of simulation is a pedagogical technology, since, it involves the interaction of the lecture and the bachelor; it contains the components of the pedagogical process (goal, tasks, content, methods, tools, forms and results of interaction); and the technology of simulation promotes personal growth of the bachelor [8]. The technology of simulation displays logic, a clear structure (goal-setting prioritization - planning, implementation and organization-control, self-control, analysis). Violation of this algorithm is ineffectual. The concept of simulation is revealed by F. Debizer, one of its founders, as "an imitative, imaginary and played out reproduction of interpersonal contacts organized around a problem situation: studying an event, solving a problem, making a decision" [9]. Other foreign educators treat the simulation as a concerned speech activity, which takes place in a clearly described realistic environment [10], [11]. A communicative challenge that requires the bachelor's personal attitude to it serves as motivation for creating a simulation in the educational process. In domestic pedagogy, the essence of this technology lies in the creation of various kinds of relations and conditions of real life, when students are not passive objects, but subjects of their activity [12].

We consider the simulation as active learning, since the student acts as a subject of learning activity and actively participates in the cognitive process, performing creative, challenging issues, in contrast to passive learning, where he is the object of educational activity and his task is only to assimilate and to reproduce the material without performing any challenging issues. The need to introduce simulation technology into the educational process is explained by the emergence of a number of problems encountered by foreign language teachers in the training of university bachelors. Specifically: a low level of motivation, a different level of language skills and a significant reduction in total hours. 


\section{Methods}

We are confident that using of the simulation technology influences bachelors' self-studying positively. First of all, this is due to the wide didactic material of Internet technologies, as well as the interest of bachelors for studying a foreign language that way. We needed to provide a number of conditions (pedagogical communication, organizational, informationpedagogical, material and technical) to develop the professional foreign-language competence as a personal quality of the future expert, providing his readiness and ability to use a foreign language in his professional activity. The presence of these conditions provides an active and purposeful bachelors' self-studying under the competent supervision of the teacher.

Developing a training course based on the simulation technology, we took into account the requirements to its content and structure: educational material, relevance, originality, cultural component, practical content, systemacity, pedagogical consistency of used techniques, monitoring system, clarity in the tasks' formulation, commenting the methods of performing tasks for the self-studying. We divided our course into some stages according to the basis of the simulation technology in bachelors' self-studying preparing.

Adaptive- diagnostic stage.

At this stage, we have the goal of introducing the bachelors to the peculiarities of self-studying in the Internet environment. There is an adaptation of bachelors to the used methods and forms of work. The teacher performs diagnostics of bachelors' self-studying level, the necessary level for the competencies forming, training skills and computer skills.

Valued-purpose stage.

The aim of this stage was to motivate the bachelors' educational activity within the simulation technology, thus forming an interest in self-studying, understanding its necessity and importance in mastering the knowledge, abilities and skills of the studied discipline for application in the future profession. Bachelors are given a direction of self-search, self-esteem, critical perception of information in the class, expression of one's own opinion.

Active - actionable stage.

At this stage the teacher monitors systematic performing of bachelors' self-studying, creates conditions for their adequate self-assessment. Eventually supervision of bachelors' self-studying has to be replaced with self-government and self-organization of the bachelor during the educational process.

Professionally creative stage.

At this stage, the teacher's task is to create conditions for self-studying and professional activities of bachelors. Its planning has to take into account the formed competences, interests, value orientations. At this stage the self-studying is rather creative. The simulation technology allows making a full use of the Internet resources' information, which we defined as necessary for the bachelors' self-studying in the university.

As a result, some structural components of selfstudying are realized: motivational-valued, program- purpose, information-activity, communicative, controlevaluation and technological.

The main task of the motivation-valued component was to stimulate the bachelors' educational activity, to form a valued attitude toward self-studying, to increase responsibility for the results of self-studying. In order to fulfil those objectives of the program-purpose component, we used a forum to inform students about the objectives of self-studying activities, the terms of its implementation for bachelors experience with the training course.

The information and substantial component was a system of self-studying that means some interconnected and interdependent types of work, logically derived from one another and controlled by the general tasks.

This system, like any other system, conformed certain didactic requirements: led to the solution of basic didactic tasks, formed self-studying skills of getting, expanding, deepening and applying the knowledge in practice, satisfied the principles of accessibility, systematicity, connection of theory with practice, conscious and creative activity, training at a high scientific level. Besides, this system was one of the main components in the educational process.

All these conditions allowed students to develop stable skills and abilities in performing various types of self-studying. Thus, speaking practice was most effectively in conditions of real communication [13].

Considering the fact that many modern bachelors use the social service VKontakte intensively enables us to message, using foreign language in synchronous mode. We asked bachelors to prepare an algorithmic dialogue in an interactive mode, print out its screenshot and send an audio file with a recorded dialogue to the teacher. This self-training mode seems quite effective to us, because it, firstly, takes little time (about 15-25 minutes, this is reflected in the printout of the screenshot) and does not distract students from other tasks. Secondly, this task allows to save the class-studying time and to use it more effectively. Besides, the interactive mode of preparing for a foreign language class can be supervised easily, that is especially important while working in big groups. It is interesting to note that the format of synchronous messaging and audio recording of the dialogue in and out-of-class format proved to be attractive for those students, who participate in interactive communication very reluctantly, because of their nature, laziness or poor knowledge of a foreign language.

On condition of algorithmized teacher's help, the efficiency of tasks' realization increases considerably. As well as any other technology, the technology of simulation is used to develop a foreign-language speech, based on the social service VKontakte, requires a clear sequence of stages and steps. Many authors offered training algorithms, depending on the training objectives and the audience of students. Also they created technologies for the foreign-language speech practice by means of Internet technologies [14, 15].

\section{Results}


We offer one of the possible algorithms for students' self-studying organizing to develop their speech skills. The first point of a preparatory stage is bachelors' experience with the purpose of their activity in the interactive social service (ISS) VKontakte in the class. The teacher explains the essence and the main stages of educational activities on the basis of the ISS VKontakte to the students, defines the subject and introduces the topic of the class, then explains what their work and the final result will be to the bachelors; explains the criteria of their work estimation; instructs which algorithm they should follow. Bachelors listen to the teacher and ask some organizational questions.

The second point of the preparatory stage is the registration training in the Community" Interactive English" in the ISS VKontakte. A teacher gives the students a page's address and the community's name in the ISS VKontakte, where a creation of documents will take place and gives printouts containing the work algorithm in the ISS VKontakte to the bachelors. The teacher explains how to post materials at the training page in the Community "Interactive English" in the ISS VKontakte and how to make changes in the earlier posted material. Then they get the address and study the work algorithm in the ISS VKontakte.

The third point of a preparatory stage is the discussion of the bachelors' information security while performing tasks in the ISS VKontakte. The teacher explains rules of information security in the ISS VKontakte.

The second stage is called procedural. At this stage, the choice of a problem task and making up the dialogue are realized. The bachelors take part in a brainstorming. The teacher writes out the bachelors' ideas on a board. Students are divided into pairs and choose the most successful problem tasks together with the teacher. The teacher gives printouts with the algorithm of trainingspeech actions in an interactive mode and a list of idioms and introductory phrases. The bachelors choose one of the problems and make a dialogue. The teacher monitors their work, helps in a case of some difficulties during their work. So, the bachelors choose a problem task, divide the roles themselves, discuss their ideas of the dialogue and define the sequence of their fragments posting at the Community "Interactive English" page in the ISS VKontakte. Further, the self - students studying is realized in the ISS VKontakte. It consists of writing and publishing documents in the ISS VKontakte. Each bachelor prepares his fragments of documents, presents them in the form of screenshots, proving his selfstudying.

The teacher monitors the self - students studying, if necessary, assists and consults on-line, monitors the placement of the completed materials on the training page of the Community "Interactive English" in the ISS VKontakte. Each bachelor reads brief directions and presses the LIKE button, confirming that he has gone over the proposed task. Then they learn the algorithm (the teacher explained in the class), and make up dialogues according to algorithm on-line, observing the time limit set for the task performing. The teacher creates and posts his podcast at the social networking site; defines a problem for creating podcasts; determines the size of bachelors' podcasts; makes sure that everyone posted them at a page of a social network. Further, bachelors record a dialogue using the Audio record podcast and attach an audio file to the task folder in the Community "Interactive English". After the publication of the dialogue in the Community "Interactive English" in the ISS VKontakte, some students present it to the whole audience. The teacher and the bachelors discuss the dialogues together.

The third stage is called the final (estimated). The bachelors argue how they managed to reveal the point of the discussed problem, apply and learn the lexical basis, understand what difficulties and why they had during the project, told what they must do to improve their work next time. The teacher estimates the work of the bachelors according to some designated criteria as planned.

\section{Conclusions}

So, the offered algorithm of bachelors' and teachers' actions shows that rather large volume of educational activity is carried out by students independently. In other words, the technology of simulation, along with the formation of bachelors' foreign communicative competence, leads to the development of the skills in self-students studying.

Besides, in our research, we used technology of simulation through using some other Internet resources, because mastering speech activity in a foreign language is possible only during training various exercises [16]. Such Internet resources include: email (tell the partner about your future profession and ask him about his); mailing lists (make the mailing list of interesting places in your city (country), subscribe for receiving messages about the country, which language you are studying); chat technologies (join the chat to discuss sanctions against the Russian Federation); forums (find a forum on "cities and countries" and participate in its work, answering at least 4 topics and setting a new one); -blogs (work in a group, make up a presentation (video) of one day work in a bank, post it in the blog and discuss the video with its visitors); videoconferences (discuss the deterioration of relations between Russia and Turkey with the partner).

So, considering some peculiarities of the "Foreign language" discipline, our experience proved that in the process of bachelors' self-studying preparing, the simulation technology provides: speech practice to each bachelor; the choice of an individual trajectory in a foreign language studying; various types of supervision of the teacher. The use of the simulation technology provides the realization of the competence-based approach in the process of the bachelors' self-studying.

\section{References}

1. A.V. Khutorskoy, Narodnoe obrazovanie 2, 55-61 (2003)

2. O.E. Lebedev, School technologies 5, 1-3 (2004) 
3. M.A. Akopova, Questions of teaching methodology at the University 12, 5-8 (2009)

4. G.S. Trofimova, Didactic bases of formation of students' communicative competence. Unpublished doctorate thesis (St. Petersburg, 2000)

5. A.A. Drobyshevsky, Organization of students' independent work with the use of computer technology training. Unpublished candidate's thesis (Saratov, 2013)

6. E.L. Makarova, Interactive educational technologies in competence-oriented teaching and learning (Sputnik+, Moscow, 2010)

7. N.B. Semenova, Vestnik of the Buryat State University 1(2), 75-78 (2014)

8. V.P. Bespalko, Components of pedagogical technology (Moscow, 1989)

9. F. Debyser, Le Françaisdans le monde 73, 40 (1970)

10. C. Aldrich, Simulations and the future of learning: an innovative (and perhaps revolutionary) approach to e-learning (Pfeifer \& Company, 2003)

11. K. Jones, Simulations in Language Teaching (Cambridge University Press, Cambridge, 1982)

12. V.I. Zagvyazinsky, Learning theory: modern interpretation (Academy, Moscow, 2007)

13. T.V. Altukhova, Communication in the social computer network "Vkontakte": the genre aspect. Unpublished candidate's thesis (Kemerovo, 2012)

14. T.Y. Pavel'eva, Methodical development of students' writing skills by means of educational Internet blog. Unpublished candidate's thesis (Moscow, 2010)

15. P.V. Sysoev, Information and communication technologies in foreign language teaching: theory and practice (Glossa-Press, Moscow, 2012)

16. A. Libshner, In the world of scientific discoveries 2(1), 142-143 (2010) 